\title{
@@ OPENACCESS CONGENITAL HEART DISEASES IN INFANTS PRESENTING WITH RESPIRATORY DISTRESS AT A TERTIARY CARE HOSPITAL
}

\author{
Mohammad Hussain, Mohsin Hayat, Mohammad Irshadæx
}

Department of Pediatrics, Medical Teaching Institute, Lady Reading Hospital, Peshawar- Pakistan.

Address for correspondence: Mohammad Irshad Department of Pediatrics, Medical Teaching Institute, Lady Reading Hospital, Peshawar - Pakistan

E-mail:

doc_irshad@yahoo.com

Date Received:

September 07, 2020

Date Revised:

March 09, 2021

Date Accepted:

March 21, 2021
This article may be cited as Hussain M, Hayat M, Irshad M. Congenital heart diseases in infants presenting with respiratory distress at a tertiary care setting. J Postgrad Med Inst 2021; 35(1): 12-4. https://doi.org/10.54079/ jpmi.35.1.2772

\section{ABSTRACT}

Objective: To determine the frequency of congenital heart diseases (CHD) in infants admitted with respiratory distress to pediatrics unit.

Methodology: This cross-sectional study was conducted on 261 infants, presenting with respiratory distress and treated as indoor patients in the pediatrics department, Lady Reading Hospital, Peshawar. Non probability purposibe sampling technique was used to enroll the sample. History was taken and infants were examined by a consultant pediatrician. The findings were recorded on a pre-designed proforma. Trans-thoracic echocardiography was performed at the cardiology unit of the same hosptial. SPSS v. 20.0 was used as a statistical tool.

Results: Out of 261 infants, $5(1.9 \%)$ were found to have congenital heart disease with a mean age of $6.0 \pm 4.6$ months. Female predominance was noted $(n=143,54.8 \%)$. Maternal age was $30.0 \pm 10.5$ years. Pulmonary stenosis was the most CHD, reported in $2(0.7 \%)$ patients, followed by ventricular septal defect, atrial septal defect and tetralogy of fallot, reported in $1(0.4 \%)$ patient each.

Conclusion: The study reported a low incidence of CHD among infants with respiratory distress and may come to attention as standalone respiratory distress in infants.

Key Words: Congenital heart disease; Infants; Respiratory distress; Pulmonary Valve Stenosis

\section{INTRODUCTION}

The cardiac and respiratory systems are interlinked with each other and changes in respiration affect cardiac output and ventilation. Congenital anomalies of the heart lead to disturbance in this system. ${ }^{1}$ The incidence of congenital heart diseases (CHD) is approximately 7-9/1000 live births in infants worldwide. ${ }^{2-4}$ In Pakistan, approximately 40,000 children are born with CHD every year. ${ }^{5}$ Incidence was reported to be $8.2 / 1000$, 10.8/1000 and 25/1000 live births in China, United States and Bangladesh, respectively. .-8 $^{6}$ Incidence in Europe was $8.2 / 1000$ which is significantly higher than North America, which was 6.9/1000. ${ }^{7}$ Differences in incidence between developed and developing countries is partly explained due to availability of diagnostic facilities. $^{9}$

In context of $\mathrm{CHD}$, changes in respiration are so significant at times, that it becomes mandatory to be familiar with the nature and dynamics of CHD and the patterns in which it affects children. Respiratory distress is one of the most common presentations of infant's admission to intensive care unit (NICU). ${ }^{10}$ This disease presents as tachypnea with respiratory rate more than 60 per minute, grunting, cyanosis, and use of accessory muscles for respiration. ${ }^{11}$ Respiratory distress without other signs of respiratory infection may be one of the signs for $\mathrm{CHD} .{ }^{12} \mathrm{At}$ term, $15 \%$ and at late preterm, 29\% infants admitted to the NICU develop significant respiratory morbidity. Before 34 weeks of gestation, respiratory problems in infants are even higher. ${ }^{10}$

There have been studies conducted in other parts of Pakistan regarding heart diseases in children. ${ }^{13,14}$ However, there is a lack of data from this part of the world. Considering the importance of the matter and its implications in the prognosis of children with resporatory distress syndrome, this study was carried out to find the frequency of CHD in infants admitted with respiratory distress symptoms at a tertiary care hospital in Peshawar - Pakistan.

\section{METHODOLOGY}

This was a cross sectional study conducted at pediatrics department, Lady Reading Hospital, Peshawar from 24 $4^{\text {th }}$ November 2018 to 24 ${ }^{\text {th }}$ May 2019. The study enrolled a sample of 261 infants. Non-probability consecutive sampling technique was used to enroll the infants. Infants with age of 2-12 months, presenting with respiratory distress, were included in the study. Infants' 
with maternal history of birth defects in previous pregnancies were excluded.

Approval was taken from hospital research and ethical board. All infants presenting with respiratory distress, meeting the inclusion criteria, admitted in ward were enrolled in the study. A written informed consent was taken after explaining the guardians, the purpose and benefits of the study and assuring them of maintaining the confidentiality.

A complete history followed by physical examination by consultant Pediatrician was conducted in the ward. All infants were subjected to transthoracic echocardiography with doppler at cardiology department of the same hospital. Patient's demographics along with maternal age were recorded on a predesigned proforma. Data were stored and analyzed using SPSS version 20.0.

\section{RESULTS}

Out of 261 infants with respiratory distress, majority $(n=151,58 \%)$ were in the age range of 2-6 months, with a mean age of $6.0 \pm 4.6$ months. Female infants $(n=143$, $54.8 \%)$ were more than male $(n=118$, $45.2 \%)$. The mean maternal age of the study population was $30.0 \pm 10.5$ years. The details are given in Table 1.

Five (1.9\%) infants had CHD, in which pulmonary stenosis (PS) was the commonest $(n=2,0.7 \%)$ followed by $1(0.4 \%)$ patient each of ventricular septal defect (VSD), atrial septal defect (ASD) and tetralogy of fallot (TOF).

\section{DISCUSSION}

Worldwide, the prevalence of $\mathrm{CHD}$ has increased substantially from $<1 / 1000$ live births in 1930 to $9 / 1000$ live births after 1995. This increase in CHD incidence is largely explained by improvement of screen- ing and diagnostic facilities with the passage of time. ${ }^{9}$ The prevalence rate varies from 1.3 per/1000 to as high as $13.28 / 1000$ children. ${ }^{3}$ This study reported prevalence of $1.9 \%$. The differences in prevalence are explained by sample size, type of echocardiography, expertise of echocardiographer and place of study. In this study, infants with respiratory distress were screened for CHD. Many small lesions like ASD $<2 \mathrm{~mm}$ and $\mathrm{PDA}<1.5 \mathrm{~mm}$ that are more prevalent in neonatal life were not included as study population comprised of infants age 2-12 months. ${ }^{5}$ Infants whose mother had history of previous birth defects were also excluded thus further contributing to lower frequency in the present study. Pulmonary stenosis can present as respiratory distress in infants. Pulmonary stenosis may resolve completely or mild PS may progress and ultimately need surgery. ${ }^{15}$ Age at diagnosis and morphology of pulmonary valve do not determine the resolution of mild PS. ${ }^{15}$

TOF, VSD and ASD may present as respiratory distress in infants with or without symptoms and signs of congestive cardiac failure. ${ }^{5,11,16}$ These septal defects and transposition of great arteries have consequences in terms of delayed management and complications with the passage of time. ${ }^{16}$ PDA is one of the most common CHD and may present as respiratory distress. ${ }^{17}$ However, no case was reported in our study probably due to the age of the study sample.

Though most CHDs are diagnosed early due to clinical presentation and signs but standalone respiratory presentation of CHDs should always be considered in differential diagnosis.

The limitation of this study was a small sample size and more such studies should be conducted nationwide, with a larger sample size, to look at the complete picture of the condition.

\section{CONCLUSION}

There is a low incidence of $\mathrm{CHD}$ among infants with respiratory distress. CHD may come to attention as standalone respiratory distress in infants. Though not a very common presentation, but CHD must be considered in differential diagnosis where no other cause can be found. Missing a diagnosis of $\mathrm{CHD}$ in time and delay in management can have profound consequences for infants, later in life.

\section{REFERENCES}

1. Mari MA, Cascudo MM, Alchieri JC. Congenital heart disease and impacts on child Development. Braz J Cardiovasc Surg. 2016;31(3):31-7. https://doi. org/10.5935/1678-9741.20160001.

2. Mulder BJM. Epidemiology of adult congenital heart disease: demographic variations worldwide. Neth Heart J. 2012;20(12):505-8. https://doi. org/10.1007/s12471-012-0335-1.

3. Saxena A, Mehta A, Sharma M, Salhan S, Kalaivani M, Ramakrishnan S, et al. Birth prevalence of congenital heart disease: A cross-sectional observational study from North India. Ann Pediatr Cardiol. 2016;9(3):205-9. https://doi. org/10.1007/s12471-012-0335-1.

4. Kabbani N, Kabbani MS, Al Taweel H. Cardiac emergencies in neonates and young infants. Avicenna J Med. 2017;7(3):16. https://doi.org/10.4103/22310770.197506.

5. Hussain S, Sabir MD, Afzal M, Asghar I. Incidence of congenital heart disease among neonates in a neonatal unit of a tertiary care hospital. J Pak Med Assoc. 2014; 64(2):175-8.

6. Yang XY, Li XF, Lü XD, Liu YL. Incidence of congenital heart disease in Beijing, China. Chin Med J (Engl). 2009;122(10):1128-

Table 1: Age distribution of Infant, mother and gender distribution of infant $(\mathrm{n}=261)$

\begin{tabular}{|c|c|c|c|c|}
\hline \multicolumn{2}{|c|}{ Age } & Number & Percentage & Mean ( \pm SD) \\
\hline \multirow{2}{*}{ Infant age } & $2-6$ month & 151 & $57.9 \%$ & \multirow{2}{*}{$6.0 \pm 4.6$} \\
\cline { 2 - 4 } & $>6-12$ month & 110 & $42.1 \%$ & \\
\cline { 2 - 4 } Maternal age & $18-30$ years & 159 & $60.9 \%$ & $30.0 \pm 10.5$ \\
\cline { 2 - 4 } & $31-40$ years & 102 & $39.1 \%$ & \\
\hline
\end{tabular}


32. https://doi.org/10.1007/s00246014-0884-8.

7. Egbe A, Uppu S, Stroustrup A, Lee S, Ho $D$, Srivastava $S$. Incidences and sociodemographics of specific congenital heart diseases in the United States of America: An evaluation of hospital discharge diagnoses. Pediatr Cardiol. 2014;35(6):97582. https://doi.org/10.1007/s00246014-0884-8.

8. Fatema NN CR, Chowdhury L. Incidence of congenital heart disease among hospital live birth in a tertiary hospital of Bangladesh. Cardiovas J. 2008;1(1):1420. https://doi.org/10.3329/cardio. v111.8199.

9. Van der Linde D, Konings EE, Slager MA, Witsenburg M, Helbing WA, Takkenberg $\mathrm{JJ}$, et al. Birth prevalence of congenital heart disease worldwide: a systematic review and meta-analysis. J Am Coll Cardiol. 2011;58(21):2241-7. https://doi. org/10.1016/j.jacc.2011.08.025.

10. Reuter S, Moser C, Baack M. Respiratory distress in the newborn. Pediatr Rev. 2014;35(10):417-29. https://doi. org/10.1542/pir.35-10-417.

11. Hermansen CL, Mahajan A. Newborn respiratory distress. Am Fam Physician. 2015;92(11):994-1002. https://doi. org/10.3126/jnps.v37i2.17623

12. Chapagain $R$, Shrestha $N$, Kayastha $M$, Shakya S, Adhikari K, Shrestha S. Spectrum of congenital heart disease in neonates admitted in an intermediate care unit of a tertiary level hospital. J Nepal Pediatr Society. 2018;37(2):174-7. https:// doi.org/10.3126/jnps.v37i2.17623.

13. Pate N, Jawed S, Nigar N, Junaid F, Wa$\operatorname{dood} A A$, Abdullah F. Frequency and pattern of congenital heart defects in a tertiary care cardiac hospital of Karachi. Pak J Med Sci. 2016;32(1):79-84. https://doi. org/10.12669/pjms.321.9029.
14. Mohammad N, Shaikh S, Memon S, Das $H$. Spectrum of heart disease in children under 5 years of age at Liaquat University Hospital, Hyderabad, Pakistan. Indian Heart J. 2014;66(1):145-9. https://doi. org/10.1016/j.ihj.2013.12.041.

15. Arain N, Moller J, Pyles L, Sivanandam S. "Vanishing" pulmonary valve stenosis. Ann Pediatr Cardiol. 2012;5(1):47-50. http:// doi.org/10.4103/0974-2069.93711.

16. Sweet LR, Keech C, Klein NP, Marshall HS, Tagbo BN, Quine D, et al. Respiratory distress in the neonate: Case definition \& guidelines for data collection, analysis, and presentation of maternal immunization safety data. Vaccine. 2017;35(48):6506- 17. https://doi. org/10.1016/j.vaccine.2017.01.046.

17. Dice JE, Bhatia J. Patent ductus arteriosus: an overview. J Pediatr Pharmacol Ther. 2007;12(3):138-46. https://doi. org/10.5863/1551-6776-12.3.138.

\section{Author's Contribution}

MH Conceived the idea, planned the study and drafted the manuscript. MH helped in the acquisition and analysis of data, editing and finalization of the manuscript. Ml also helped in the acquisition and analysis of data, editing and finalization of the manuscript. Authors agree to be accountable for all aspects of the work in ensuring that questions related to the accuracy or integrity of any part of the work are appropriately investigated and resolved.

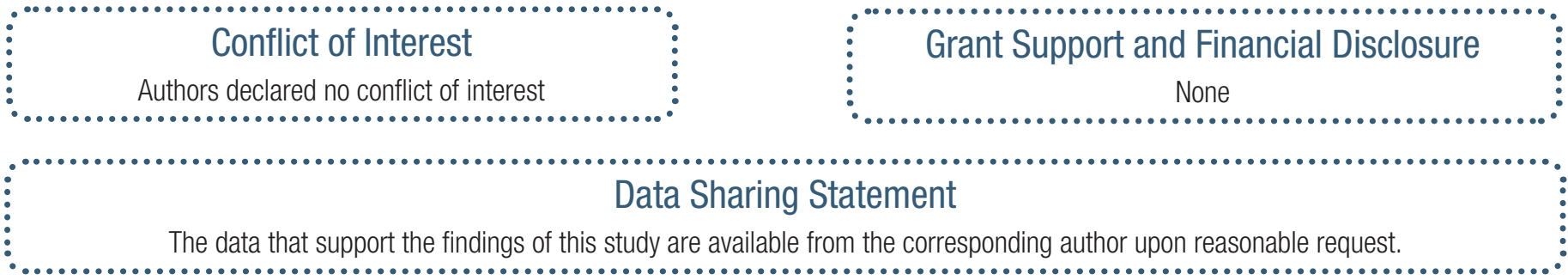

